\title{
A Nanomechanical Investigation of Three Putative Anti-Erosion Agents: Remineralisation and Protection against Demineralisation
}

\author{
Ahmed Z. Abdullah, ${ }^{1,2}$ Anthony J. Ireland, ${ }^{2}$ \\ Jonathan R. Sandy, ${ }^{2}$ and Michele E. Barbour ${ }^{1}$ \\ ${ }^{1}$ Oral Nanoscience, School of Oral \& Dental Sciences, University of Bristol, Bristol BS1 2LY, UK \\ ${ }^{2}$ Child Dental Health, School of Oral \& Dental Sciences, University of Bristol, Bristol BS1 2LY, UK \\ Correspondence should be addressed to Michele E. Barbour, m.e.barbour@bristol.ac.uk \\ Received 3 May 2012; Revised 30 May 2012; Accepted 21 June 2012 \\ Academic Editor: Annette Wiegand
}

Copyright @ 2012 Ahmed Z. Abdullah et al. This is an open access article distributed under the Creative Commons Attribution License, which permits unrestricted use, distribution, and reproduction in any medium, provided the original work is properly cited.

\begin{abstract}
An increasing interest in dental erosion as a clinical and scientific phenomenon has led to concerted efforts to identify agents which might protect against erosion. In this study, nanoindentation was used to investigate inhibition of erosive enamel demineralisation over time scales with direct clinical relevance. Nanohardness of polished human enamel specimens $(n=8$ per group) was measured at baseline (B), after demineralisation (D1: citric acid, $0.3 \% \mathrm{w} / \mathrm{v}, \mathrm{pH} 3.20,20 \mathrm{~s}$ ), after treatment (T), and after a second demineralisation (D2: as above). Data were analysed using repeated measures ANOVA. All specimens exhibited a similar reduction in nanohardness B-D1 in the range 35.2-39.5\%. The positive control solution (saturated hydroxyapatite solution) and $4500 \mathrm{mg} / \mathrm{L}$ fluoride as NaF significantly increased nanohardness D1-T by $19.9 \%$ and $24.1 \%$, respectively, whereas $1400 \mathrm{mg} / \mathrm{L}$ fluoride as $\mathrm{NaF}$, casein phosphopeptide-amorphous calcium phosphate mousse and negative control (deionised water) had no significant effect. Nanohardness at D2 was indistinguishable for all groups, with total reduction in nanohardness B-D2 of $31.6 \%(4500 \mathrm{mg} / \mathrm{L}$ fluoride), 35.2\% (positive control), 39.9\% (1400 mg/L fluoride), 42.4\% (negative control), and 43.7\% (CPP-ACP product). In summary, $4500 \mathrm{mg} / \mathrm{L}$ fluoride significantly increased the nanohardness of previously demineralised enamel and resulted in the smallest total reduction in nanohardness but there were few statistically significant differences among the groups.
\end{abstract}

\section{Introduction}

Dental erosion is widely acknowledged as a common problem among children, adolescents, and adults [1]. There is a great deal of interest in the development and evaluation of treatments which might reduce the severity of erosion. Of these, salts of fluoride have received perhaps the most attention, and there is convincing evidence that applications of fluoride, particularly at high concentrations, can provide protection against erosion [2]. A number of different fluoride salts have been investigated, including stannous (tin) fluoride $[3,4]$, amine fluoride [3], titanium fluoride $[5,6]$, zirconium, and hafnium fluoride [6], but sodium fluoride has been the subject of the most studies owing to its widespread use in commercially available oral care products.
Another agent which has received attention with regard to its ability to protect against erosion is a peptide of the bovine milk protein casein, casein phosphopeptide, in association with nanoparticles of calcium phosphate [7]. This is most commonly described in the literature and in marketing material as CPP-ACP (casein phosphopeptide-amorphous calcium phosphate). It has been incorporated, under the name Recaldent, into various products, one of the most successfully marketed being GC Tooth Mousse (Europe and Australia) or MI Paste (Japan, North and South America) (GC Corporation, Japan) [8].

Some investigations of agents which protect against erosion published in the research literature utilise prolonged exposures to the treatment agents. There are instances in which it could be argued that these are difficult to justify_-it 
is hard to imagine the clinical relevance of a study where the tooth specimens are treated with a solution or paste for hours or even days before the erosive challenge is applied. Other studies utilise a cycling approach where the treatment and/or erosion/wear and/or saliva exposure are alternated with the intention of mimicking the changing oral environment over a period of several hours or days. Thus although in some cases the total exposure time to the treatment agent may be rather long, this is interspersed with acid and saliva exposures and thereby represents an accelerated aging model of erosion. In other cases the treatment may only be applied once and then a number of cycles of demineralisation and remineralisation are applied, in part to give sufficient erosive tooth loss to be detectable using laboratory techniques [9, 10]. As long as each exposure is of clinically relevant duration [11], these studies are much more justifiable and, while they may overestimate the amount of wear that would be seen clinically [12], are very useful in assessing the relative merits of protective strategies. There is also benefit in developing experimental models in which the treatment and erosion phases are very short, comparable to those seen in a single in vivo event, such as a single brushing of the teeth and/or a single intake of drink. Some recent examples of such studies can be found in references [13-15].

The aim of this study was to investigate three potentially erosion-preventive measures in a model which allows for single, clinically relevant exposure times. The experiment was designed such that we could assess both the effect of the treatments on the nanohardness of softened enamel (whether the treatment had caused any remineralisation) and whether the treatments affected the nanohardness of the same enamel after a subsequent, second erosive challenge (whether the treatment inhibited further demineralisation).

\section{Material and Methods}

2.1. Specimen Preparation. Forty-four human enamel specimens were prepared by sectioning healthy, sound enamel from the mesial, distal, buccal, and lingual surfaces of 22 human premolars and molars, which had previously been sterilised by immersion in $20000 \mathrm{ppm}$ available chlorine for $24 \mathrm{~h}$, followed by immersion in $4 \%$ formaldehyde for 7 days, and subsequently long-term storage in $70 \%$ ethanol. The specimens were randomly assigned to five groups of 8 specimens. Specimens measuring 1-2 mm wide (around the perimeter of the tooth) and $2-3 \mathrm{~mm}$ long (along the central axis of the tooth) were sectioned from the teeth using a watercooled, diamond tipped annular saw (Microsilice 2; Metals Research, Royston, UK) and mounted in epoxy resin (Stycast; Hitek Electronic Materials, Scunthorpe, UK) using silicone molds. The natural surface of the enamel was lapped using silicon carbide paper of 120 and 1200 grit size under slow water flow for the minimum possible time needed to remove any thin layer of resin that had flowed over the enamel surface and to remove the very outer enamel to provide a flat working surface. The specimens were then ultrasonicated in industrial methylated spirit (IMS) for approximately $2 \mathrm{~min}$ at room temperature to remove polishing debris and polished using an aqueous slurry of $0.25 \mu \mathrm{m}$ aluminium oxide to achieve a mirror finish and ultrasonicated again in IMS. All specimens were carefully inspected for lesions or damage before they were accepted for use in the study. Specimens were also assessed at D1 (see below) for their nanohardness and any outlying specimens, with nanohardness more than 1.5 standard deviations different from the mean, were eliminated and replaced with new specimens. This was done in order to exclude specimens that proved to be unusually susceptible, or resistant, to demineralisation and applied to 4 specimens $(10 \%)$ in this study giving a final $n=40$.

2.2. Nanoindentation. A nanoindentation system comprising a diamond-tipped Berkovich tip and vertical engagement with continual monitoring and control of vertical displacement was used (Triboscope; Hysitron Inc., Minneapolis, MN, USA) on an atomic force microscope (Nanoscope IIIa; Digital Instruments, Santa Barbara, CA, USA). Five widely spaced nanoindentations were performed on each specimen at each time point of the experiment and the mean from each specimen was used for statistical analysis. The AFM was used, with the Berkovich tip, to scan an area of $5 \times 5 \mu \mathrm{m}$ prior to each indent to establish that the specimen was free from debris or microscopic scratches or cracks, and after indentation to check that the indent was equilateral and thus that the tip was engaged normal to the specimen surface. The nanoindentation data were analysed using Hysitron software using the Oliver \& Pharr method to calculate nanohardness [16].

\subsection{Study Regime. Specimens were treated as follows:}

Baseline nanohardness (B) measured on polished, untreated specimens

D1: 1st demineralisation phase

D1 nanohardness measured

T: treatment phase with one of three test treatments or positive or negative control

T nanohardness measured

D2: 2nd demineralisation phase

D2 nanohardness measured.

2.4. Demineralisation. The demineralising solution was $0.3 \% \mathrm{w} / \mathrm{v}$ citric acid monohydrate (Fisher Scientific, Loughborough, UK) adjusted to $\mathrm{pH} 3.20$ using $\mathrm{KOH}$. The specimens were attached to a disc $30 \mathrm{~mm}$ in diameter which was mounted on a quantitative overhead stirrer (R50D; CAT, Staufen, Germany) in order to provide a standardised method for agitation [17]. The angular velocity of the stirrer was adjusted to give an equivalent linear velocity of the specimens in the solution of $0.25 \mathrm{~m} / \mathrm{s}$. Specimens were exposed to acid for 20 seconds at room temperature. After each acid exposure, specimens were rinsed by immersion in deionised water for 60 seconds.

2.5. Treatment. Three test treatments were investigated alongside positive and negative control solutions. 
2.5.1. Test Treatments. Two sodium fluoride solutions, with fluoride concentrations of $1400(\mathrm{pH} 6.68)$ and $4500(\mathrm{pH}$ 6.74) $\mathrm{mg} / \mathrm{L}$ (Fisher Scientific, Loughborough, UK) were used, and a CPP-ACP-containing mousse product, hereafter referred to as CPP-ACP product (GC Tooth Mousse, GC Corporation, Tokyo, Japan).

2.5.2. Control Solutions. The negative control was deionised water. The positive control was a solution saturated with respect to hydroxyapatite (HA), which was prepared by incrementally adding $0.1 \mathrm{~g}$ aliquots of HA powder (Sigma Aldrich, Gillingham, UK) to $1 \mathrm{~L}$ deionised water at $70^{\circ} \mathrm{C}$ under moderate stirring until no further hydroxyapatite dissolved. The solution was maintained at $70^{\circ} \mathrm{C}$ for 72 hours then left to cool slowly to room temperature and used immediately.

2.6. Exposure to Treatment Solutions. Specimens were attached to a disc to facilitate their handling. In the groups tested with fluoride or deionised water, specimens were immersed in the solution for 2 minutes without stirring. For the positive control, specimens were immersed without agitation for 60 minutes. The final group was covered with CPPACP product for 5 minutes according to the manufacturer's recommendation. After treatment, all specimens were rinsed with deionised water for 60 seconds.

2.7. Scanning Electron Microscopy. Scanning electron micrographs of enamel specimens at D2 were obtained using a Phenom scanning electron microscope (FEI, Netherlands) at nominal magnifications of 10000x and 20000x.

2.8. Statistical Analysis. Nanohardness data were analysed by repeated measures ANOVA using SPSS statistical software package for Windows, version 16.0 (IBM Corporation, New York, USA).

\section{Results}

The mean nanohardness of the specimens as a function of stage and treatment and standard deviations are given in Table 1. In the reporting and discussion of the results, data are expressed as percent change from baseline nanohardness in order to provide a simple comparison of the effects of the treatments by eliminating the need for the reader to continually refer back to the baseline nanohardness. However, raw data can be seen in Table 1 to allow a comparison of the actual nanohardness values.

All specimens displayed a statistically significant softening from B to D1, with reduction in nanohardness in the range $35.2-39.5 \%$. All specimens showed a numerical increase in hardness from D1 to $\mathrm{T}$, but this was only statistically significant for the positive control $(19.9 \%$ increase in nanohardness) and the $4500 \mathrm{mg} / \mathrm{L}$ fluoride $(24.1 \%$ increase in nanohardness). All specimens showed a numerical softening from $\mathrm{T}$ to $\mathrm{D} 2$, but this was only statistically significant for $1400 \mathrm{mg} / \mathrm{L}$ fluoride (22.2\% decrease in nanohardness) and CPP-ACP mousse (24.8\% decrease in nanohardness).
TABle 1: Mean nanohardness and standard deviations (GPa) of human enamel specimens as a function of stage and treatment. B: at baseline, D1: after first demineralisation, T: after treatment, D2: after second demineralisation.

\begin{tabular}{lcccc}
\hline \multirow{2}{*}{ Treatment } & \multicolumn{4}{c}{ Mean nanohardness (GPa) } \\
& $\mathrm{B}$ & $\mathrm{D} 1$ & $\mathrm{~T}$ & $\mathrm{D} 2$ \\
\hline $\begin{array}{l}\text { Negative } \\
\text { control }\end{array}$ & $3.98(0.37)$ & $2.58(0.32)$ & $2.76(0.35)$ & $2.29(0.25)$ \\
$1400 \mathrm{mg} / \mathrm{L} \mathrm{F}$ & $4.25(0.66)$ & $2.82(0.32)$ & $3.28(0.68)$ & $2.55(0.28)$ \\
$4500 \mathrm{mg} / \mathrm{L} \mathrm{F}$ & $4.12(0.52)$ & $2.56(0.27)$ & $3.38(0.54)$ & $2.82(0.49)$ \\
$\begin{array}{l}\text { CPP-ACP } \\
\text { product }\end{array}$ & $4.30(0.53)$ & $2.78(0.36)$ & $3.22(0.39)$ & $2.42(0.27)$ \\
$\begin{array}{l}\text { Positive } \\
\text { control }\end{array}$ & $4.72(0.46)$ & $2.86(0.29)$ & $3.56(0.50)$ & $3.06(0.42)$ \\
\hline
\end{tabular}

The overall reduction in hardness from $\mathrm{B}$ to $\mathrm{D} 2$ was $\mathrm{CPP}-$ ACP product (43.7\%), negative control (42.4\%), $1400 \mathrm{mg} / \mathrm{L}$ fluoride (39.9\%), positive control (35.2\%), and $4500 \mathrm{mg} / \mathrm{L}$ fluoride $(31.6 \%)$. The statistical analysis indicated that there was a statistically significant difference between the positive and negative controls, but not between either control and the test solutions.

Scanning electron micrographs of a representative selection of the enamel samples are shown in Figures $1(a)-1(j)$. Areas of the specimens show the characteristic honeycomb pattern of etched enamel, interspersed with areas where the original polishing lines are apparent. This demonstrates that the etching was at an early stage without bulk tissue loss. No surface deposits were observed in any specimen group and all specimens from all treatment groups had a similar appearance.

\section{Discussion}

In this in vitro study we investigated three agents with respect to their capacity to protect human enamel against dietary acid-mediated demineralisation. The use of nanoindentation allowed us to employ exposure times for acid and treatment that are relevant to a single clinical application, as was recommended in a recent thorough review of laboratory erosion and abrasion models [12]. The study design allowed the investigation of whether the test agents increased the nanohardness of previously demineralised enamel, and also whether the test agents protected the enamel against subsequent demineralisation.

Nanohardness was used as the outcome measurement and is interpreted as an indication of the extent of demineralisation that had taken place. Nanoindentation is recognised as one of the most sensitive methods for investigating enamel demineralisation $[10,14]$. It has been shown that enamel nanohardness reduces as a function of acid exposure time and thus can be used as an indication of the extent of erosionlike demineralisation that has taken place up to exposure times of around 5 minutes [14, 18]. A correlation between nanohardness and the mineral content of calcium and phosphate-like species $\mathrm{PO}_{\mathrm{x}} \mathrm{H}_{\mathrm{y}}$ in demineralised human enamel has been previously demonstrated [19], and so 


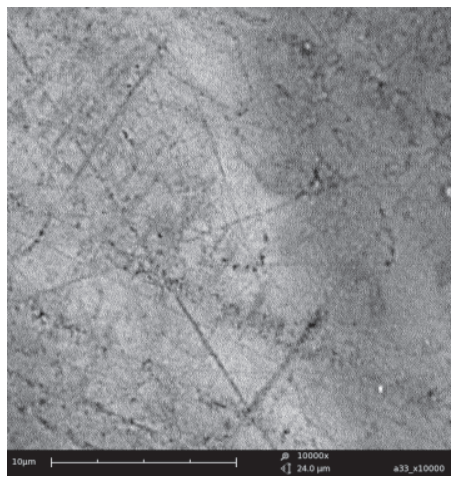

(a)

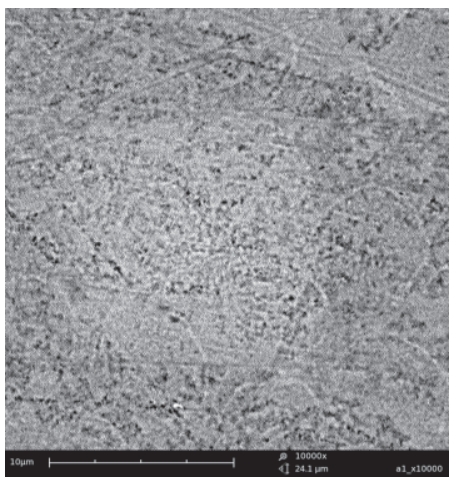

(c)

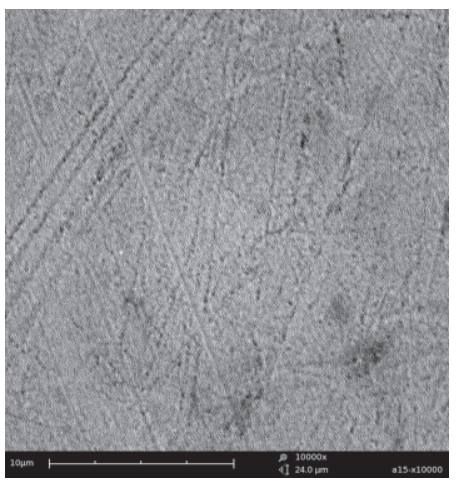

(e)

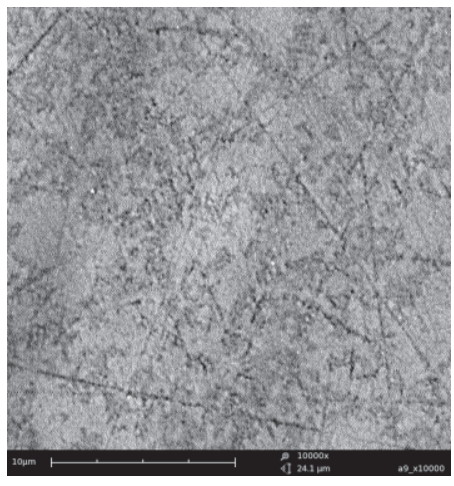

(g)

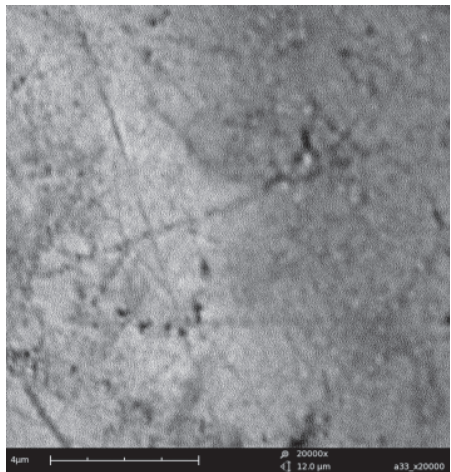

(b)

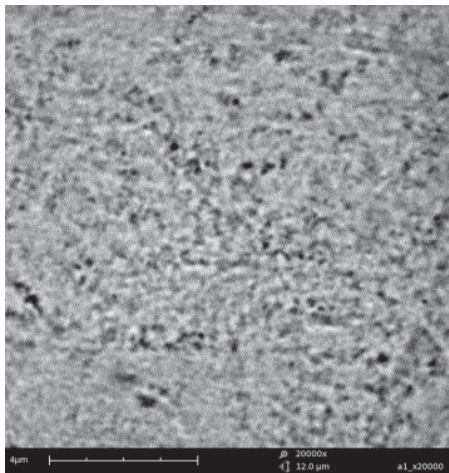

(d)

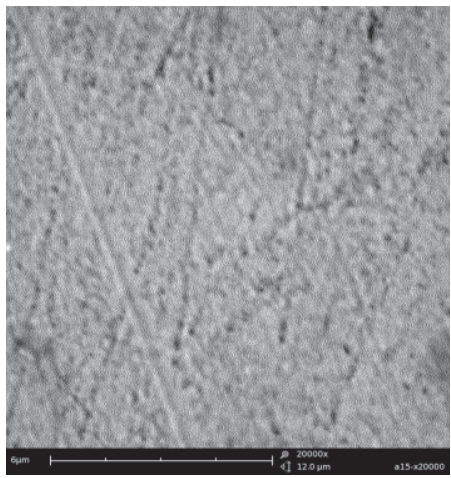

(f)

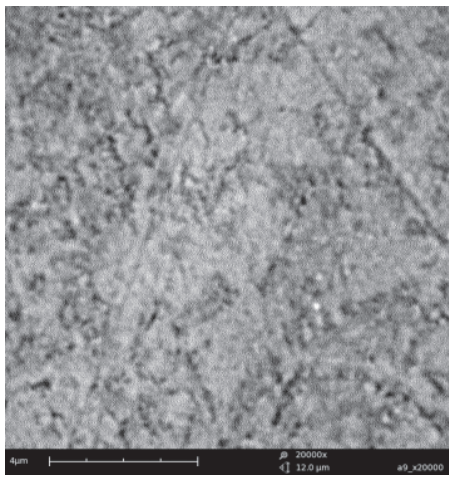

(h)

Figure 1: Continued. 


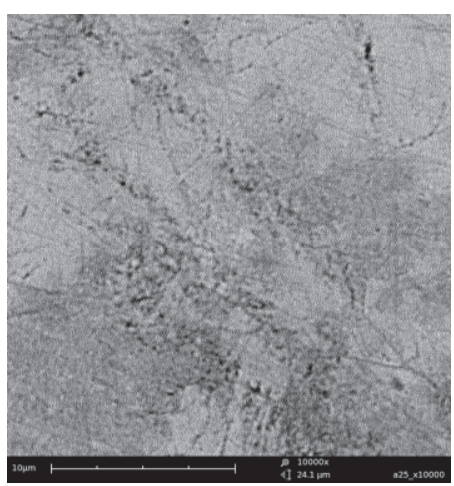

(i)

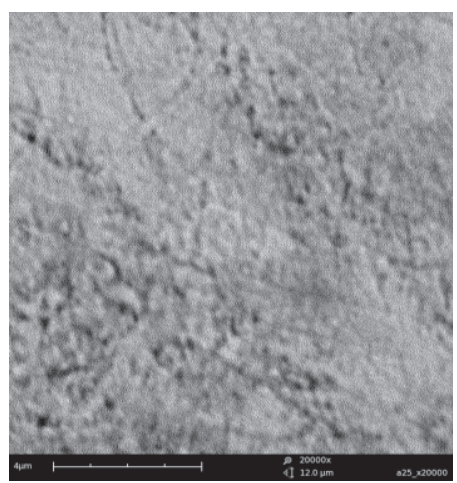

(j)

FIgURE 1: Scanning electron micrographs of enamel specimens after D2. (a) and (b) negative control; (c) and (d) 1400 mg/L F; (e) and (f) $4500 \mathrm{mg} / \mathrm{L} \mathrm{F}$; (g) and (h) CPP-ACP product; (j) positive control. Scale bars represent $10 \mu \mathrm{m}$ ((a), (c), (e), (g), (i)) and $4 \mu \mathrm{m}$ ((b), (d), (f), (h), (j)).

nanoindentation was selected for use in this study. This is because it offers the possibility to investigate enamel demineralisation and remineralisation at very early stages, using time scales of relevance to clinical exposure [20], where the bulk tissue is still in place, and where only localised mineral depletion within the enamel structure has occurred, as indicated in Figure 1 [18].

Experimental conditions for the treatment stage of the study were, likewise, designed to some extent to mimic the clinical situation. The fluoride solutions were applied for 2 minutes, since the recommendation for toothbrushing is typically to brush for 2 minutes, and the concentration of fluoride in saliva is quite rapidly depleted after the brushing ceases. That is not to say each tooth receives 2 minutes' brushing-the figure is more likely to be of the order of 5 seconds [12] - but there will be an elevated concentration of fluoride in the mouth throughout the brushing process. The fluoride concentrations were chosen as representative of mass market toothpastes $(1400 \mathrm{mg} / \mathrm{L})$ and comparable to prescription-only products $(4500 \mathrm{mg} / \mathrm{L})$. The CPP-ACP product was applied according to the manufacturer's guidelines, by smoothing onto the enamel surface and allowing it to remain undisturbed for 5 minutes. The positive control, saturated hydroxyapatite solution, was applied to the enamel specimens for 60 minutes to represent a period of inactivity during the day where the tooth surface is bathed in saliva.

The results indicate that 2 minutes' exposure to $4500 \mathrm{mg} / \mathrm{L}$ fluoride solution significantly increased the nanohardness of demineralised enamel, but $1400 \mathrm{mg} / \mathrm{L}$ fluoride solution did not. Furthermore, specimens treated with $4500 \mathrm{mg} / \mathrm{L}$ fluoride did not display significant softening when exposed to acid for a second time, whereas those treated with $1400 \mathrm{mg} / \mathrm{L}$ fluoride did soften significantly. Thus it appears that $4500 \mathrm{mg} / \mathrm{L}$ fluoride solution did, under these experimental conditions, provide both some rehardening of the enamel and some protection against subsequent demineralisation. We would interpret these results as signifying that the $4500 \mathrm{mg} / \mathrm{L}$ fluoride solution caused some precipitation of mineral within the softened surface enamel and that this resulted in both an increase in hardness and a reduced susceptibility to subsequent dissolution. This may suggest that the mineral deposited was fluorhydroxyapatite rather than calcium fluoride, and the moderately low concentration of fluoride and near-neutral $\mathrm{pH}$ of the treatment solution would support this inference [21]. The scanning electron micrographs in Figures 1(e) and 1(f) would also appear to offer support to this hypothesis, as they did not reveal any evidence of deposits on the surface, for instance of calcium fluoride. It should be noted, however, that the increase in enamel nanohardness afforded by treatment with $4500 \mathrm{mg} / \mathrm{L}$ fluoride was somewhat modest, and the resultant nanohardness after stage $\mathrm{T}$ was still some $18 \%$ lower than at baseline. The $1400 \mathrm{mg} / \mathrm{L}$ fluoride solution was either unable to produce such mineral deposits or those that were effected were insufficient to significantly increase nanohardness or reduce subsequent softening. A number of authors have sought to investigate the protective effects of fluoride compounds, and particularly sodium fluoride, against dental erosion [2]. A dose response effect showing increased protection at elevated sodium fluoride concentration has been observed both in vitro [13, 22-24] and in situ [25], although other studies have failed to reveal a dependence on fluoride concentration $[26,27]$.

Specimens that were demineralised and then treated with CPP-ACP product for 5 minutes, as recommended by the manufacturer, did not display a significant increase in nanohardness; neither did the treatment with CPP-ACP product provide any protection against subsequent demineralisation. There was no evidence of any of the product on the surface after D2 (Figures $1(\mathrm{~g})$ and $1(\mathrm{~h})$ ). In a recent study, a significant increase in enamel microhardness was observed after treatment with the same CPP-ACP product [28], but the minimum exposure time investigated was 2 weeks. The contact time with the CPP-ACP product was, therefore, some 4000 times longer than in the present study. Another study using a 15-minute exposure to CPP-ACP demonstrated that enamel wear, as distinct from softening, was reduced by this treatment [29]. On the other hand, 
CPP-ACP product also failed to protect enamel against a subsequent erosive challenge in a model using 5 cycles of treatment, erosion, and remineralisation, although it was able to provide some protection when applied in conjunction with fluoride [30]. In a study where enamel specimens were eroded, placed in the mouth to facilitate remineralisation, treated with CPP-ACP product for 3 minutes applied either ex vivo or in situ, and finally replaced in the mouth for a further period of remineralisation, the CPP-ACP product did not confer any significant rehardening or protection of the enamel specimens [31]. It is plausible that putative protective effects of CPP-ACP are time dependent, with a significant effect only becoming apparent with long and/or repeated exposures.

\section{Conclusion}

Only two treatments significantly rehardened the softened enamel (from D1 to T): the positive control and $4500 \mathrm{mg} / \mathrm{L}$ fluoride (as sodium fluoride). The CPP-ACP product, $1400 \mathrm{mg} / \mathrm{L}$ fluoride and negative control solutions did not reharden the enamel. The total reduction in nanohardness (from B to D2) was $31.6 \%$ (4500mg/L fluoride), $35.2 \%$ (positive control), 39.9\% (1400 mg/L fluoride), 42.4\% (negative control), and $43.7 \%$ (CPP-ACP product), but over the entire time course the repeated measures ANOVA indicated that only the positive and negative controls differed to a statistically significant degree.

\section{References}

[1] A. K. Johansson, R. Omar, G. E. Carlsson, and A. Johansson, "Dental erosion and its growing importance in clinical practice: from past to present," International Journal of Dentistry, vol. 2012, Article ID 632907, 17 pages, 2012.

[2] A. C. Magalhães, A. Wiegand, D. Rios, M. A. R. Buzalaf, and A. Lussi, "Fluoride in dental erosion," Monographs in Oral Science, vol. 22, pp. 158-170, 2011.

[3] A. Wiegand, D. Bichsel, A. C. Magalhães, K. Becker, and T. Attin, "Effect of sodium, amine and stannous fluoride at the same concentration and different $\mathrm{pH}$ on in vitro erosion," Journal of Dentistry, vol. 37, no. 8, pp. 591-595, 2009.

[4] C. Ganss, M. Hardt, A. Lussi, A. K. Cocks, J. Klimek, and N. Schlueter, "Mechanism of action of tin-containing fluoride solutions as anti-erosive agents in dentine-an in vitro tinuptake, tissue loss, and scanning electron microscopy study," European Journal of Oral Sciences, vol. 118, no. 4, pp. 376-384, 2010.

[5] A. C. Magalhães, L. P. Comar, D. Rios, A. C. B. Delbem, and M. A. R. Buzalaf, "Effect of a $4 \%$ titanium tetrafluoride $\left(\mathrm{TiF}_{4}\right)$ varnish on demineralisation and remineralisation of bovine enamel in vitro," Journal of Dentistry, vol. 36, no. 2, pp. 158$162,2008$.

[6] A. Wiegand, B. Hiestand, B. Sener, A. C. Magalhães, M. Roos, and T. Attin, "Effect of $\mathrm{TiF}_{4}, \mathrm{ZrF}_{4}, \mathrm{HfF}_{4}$ and $\mathrm{AmF}$ on erosion and erosion/abrasion of enamel and dentin in situ," Archives of Oral Biology, vol. 55, no. 3, pp. 223-228, 2010.

[7] E. C. Reynolds, "Casein phosphopeptide-amorphous calcium phosphate: the scientific evidence," Advances in Dental Research, vol. 21, no. 1, pp. 25-29, 2009.
[8] N. J. Cochrane, F. Cai, N. L. Huq, M. F. Burrow, and E. C. Reynolds, "Critical review in oral biology \& medicine: new approaches to enhanced remineralization of tooth enamel," Journal of Dental Research, vol. 89, no. 11, pp. 1187-1197, 2010.

[9] M. E. Barbour and J. S. Rees, "The laboratory assessment of enamel erosion: a review," Journal of Dentistry, vol. 32, no. 8, pp. 591-602, 2004.

[10] T. Attin, "Methods for assessment of dental erosion," Monographs in Oral Science, vol. 20, pp. 152-172, 2006.

[11] R. P. Shellis, C. Ganss, Y. Ren, D. T. Zero, and A. Lussi, "Methodology and models in erosion research: discussion and conclusions," Caries Research, vol. 45, supplement 1, pp. 69-77, 2011.

[12] A. Wiegand and T. Attin, "Design of erosion/abrasion studies-insights and rational concepts," Caries Research, vol. 45, 1, pp. 53-59, 2011.

[13] A. J. White, S. B. Jones, M. E. Barbour, D. R. Churchley, L. H. Gracia, and G. D. Rees, "Inhibition of erosive dissolution by sodium fluoride: evidence for a dose response," Journal of Dentistry, vol. 40, no. 8, pp. 654-660, 2012.

[14] A. J. White, C. Yorath, V. Ten Hengel, S. D. Leary, M. C. D. N. J. M. Huysmans, and M. E. Barbour, "Human and bovine enamel erosion under "single-drink" conditions," European Journal of Oral Sciences, vol. 118, no. 6, pp. 604-609, 2010.

[15] H. Yu, F. J. Wegehaupt, M. Zaruba et al., "Erosion-inhibiting potential of a stannous chloride-containing fluoride solution under acid flow conditions in vitro," Archives of Oral Biology, vol. 55, no. 9, pp. 702-705, 2010.

[16] W. C. Oliver and G. M. Pharr, "Improved technique for determining hardness and elastic modulus using load and displacement sensing indentation experiments," Journal of Materials Research, vol. 7, no. 6, pp. 1564-1583, 1992.

[17] C. A. Hemingway, D. M. Parker, M. Addy, and M. E. Barbour, "Erosion of enamel by non-carbonated soft drinks with and without toothbrushing abrasion," British Dental Journal, vol. 201, no. 7, pp. 447-450, 2006.

[18] M. E. Barbour, D. M. Parker, G. C. Allen, and K. D. Jandt, "Human enamel erosion in constant composition citric acid solutions as a function of degree of saturation with respect to hydroxyapatite," Journal of Oral Rehabilitation, vol. 32, no. 1, pp. 16-21, 2005.

[19] M. E. Dickinson, K. V. Wolf, and A. B. Mann, "Nanomechanical and chemical characterization of incipient in vitro carious lesions in human dental enamel," Archives of Oral Biology, vol. 52, no. 8, pp. 753-760, 2007.

[20] N. Schlueter, A. Hara, R. P. Shellis, and C. Ganss, "Methods for the measurement and characterization of erosion in enamel and dentine," Caries Research, vol. 45, supplement 1, pp. 1323, 2011.

[21] H. G. McCann, "Reactions of fluoride ion with hydroxyapatite," The Journal of Biological Chemistry, vol. 201, no. 1, pp. 247-259, 1953.

[22] L. H. Gracia, G. D. Rees, A. Brown, and C. E. Fowler, "An in vitro evaluation of a novel high fluoride daily mouthrinse using a combination of microindentation, 3D profilometry and DSIMS," Journal of Dentistry, vol. 38, no. 3, pp. S12-S20, 2010.

[23] A. Venasakulchai, N. A. Williams, L. H. Gracia, and G. D. Rees, "A comparative evaluation of fluoridated and non-fluoridated mouthrinses using a 5-day cycling enamel erosion model," Journal of Dentistry, vol. 38, no. 3, pp. S21-S29, 2010. 
[24] R. S. Austin, J. M. Rodriguez, S. Dunne, R. Moazzez, and D. W. Bartlett, "The effect of increasing sodium fluoride concentrations on erosion and attrition of enamel and dentine in vitro," Journal of Dentistry, vol. 38, no. 10, pp. 782-787, 2010.

[25] B. Maggio, R. G. Guibert, S. C. Mason et al., "Evaluation of mouthrinse and dentifrice regimens in an in situ erosion remineralisation model," Journal of Dentistry, vol. 38, no. 3, pp. S37-S44, 2010.

[26] D. Rios, A. C. Magalhães, R. O. B. Polo, A. Wiegand, T. Attin, and M. A. R. Buzalaf, "The efficacy of a highly concentrated fluoride dentifrice on bovine enamel subjected to erosion and abrasion," Journal of the American Dental Association, vol. 139, no. 12, pp. 1652-1656, 2008.

[27] D. C. Messias, F. A. Maeda, C. P. Turssi, and M. C. Serra, "Effect of dentifrices against hydrochloric acid-induced erosion," Oral Health \& Preventive Dentistry, vol. 9, no. 3, pp. 269-273, 2011.

[28] S. L. Zhou, J. Zhou, S. Watanabe, K. Watanabe, L. Y. Wen, and K. Xuan, "In vitro study of the effects of fluoride-releasing dental materials on remineralization in an enamel erosion model," Journal of Dentistry, vol. 40, no. 3, pp. 255-263, 2012.

[29] B. Willershausen, B. Schulz-Dobrick, and C. Gleissner, "In vitro evaluation of enamel remineralisation by a casein phosphopeptide-amorphous calcium phosphate paste," Oral Health \& Preventive Dentistry, vol. 7, no. 1, pp. 13-21, 2009.

[30] C. P. Turssi, F. A. Maeda, D. C. F. Messias, F. C. R. Neto, M. C. Serra, and D. Galafassi, "Effect of potential remineralizing agents on acid softened enamel," American Journal of Dentistry, vol. 24, no. 3, pp. 165-168, 2011.

[31] F. J. Wegehaupt, T. T. Tauböck, A. Stillhard, P. R. Schmidlin, and T. Attin, "Influence of extra- and intra-oral application of CPP-ACP and fluoride on re-hardening of eroded enamel," Acta Odontologica Scandinavica, vol. 70, no. 3, pp. 177-183, 2012. 


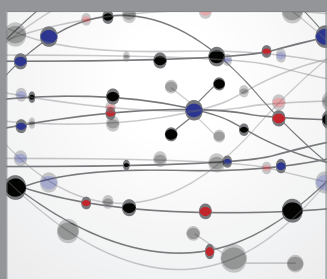

The Scientific World Journal
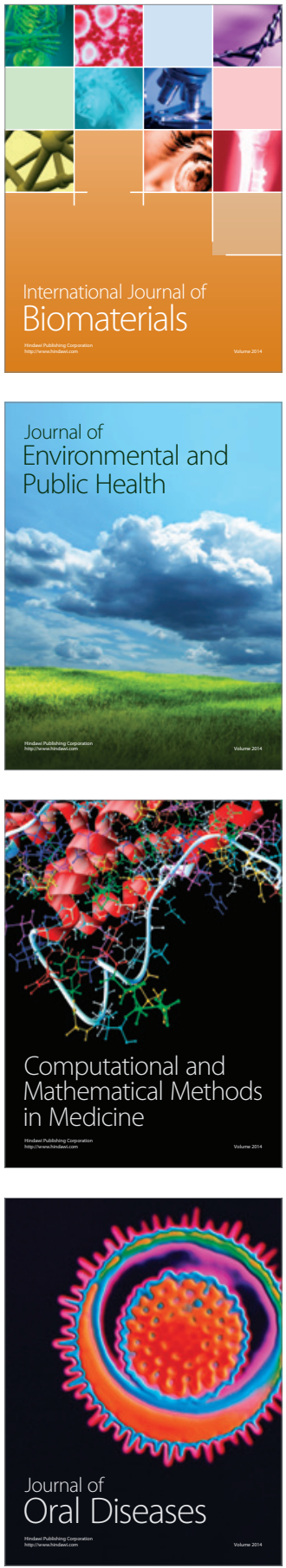
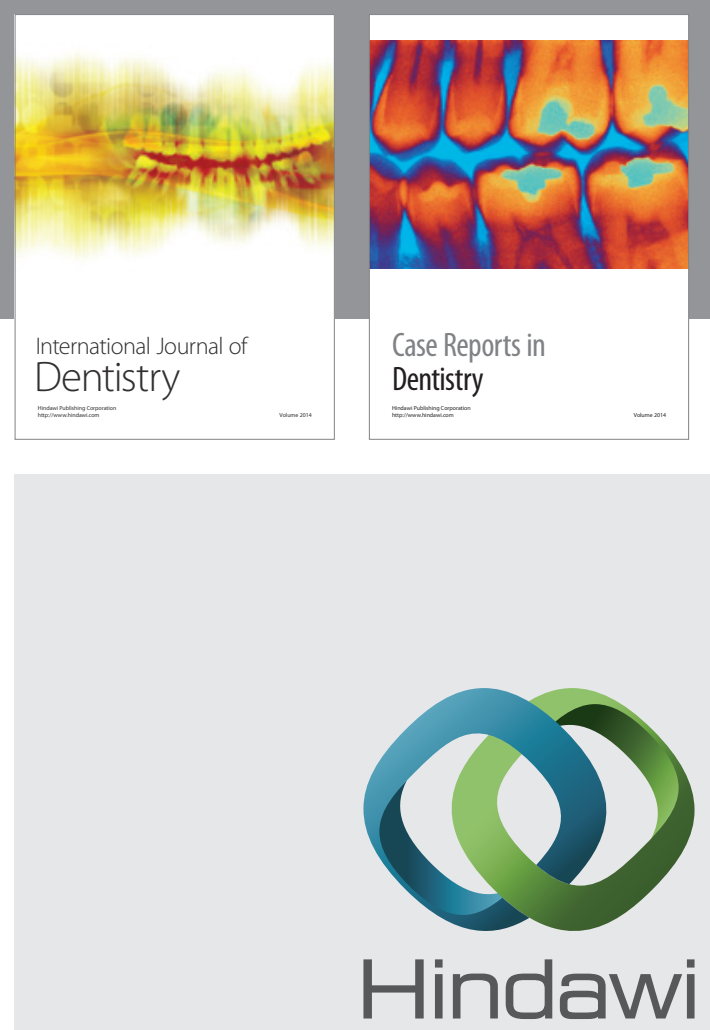

Submit your manuscripts at

http://www.hindawi.com
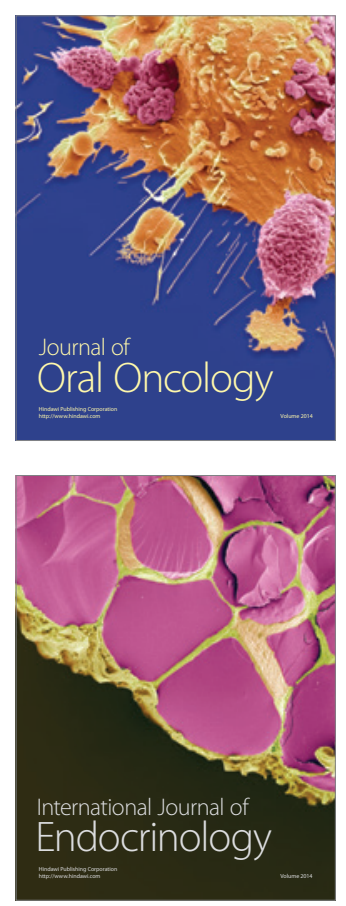
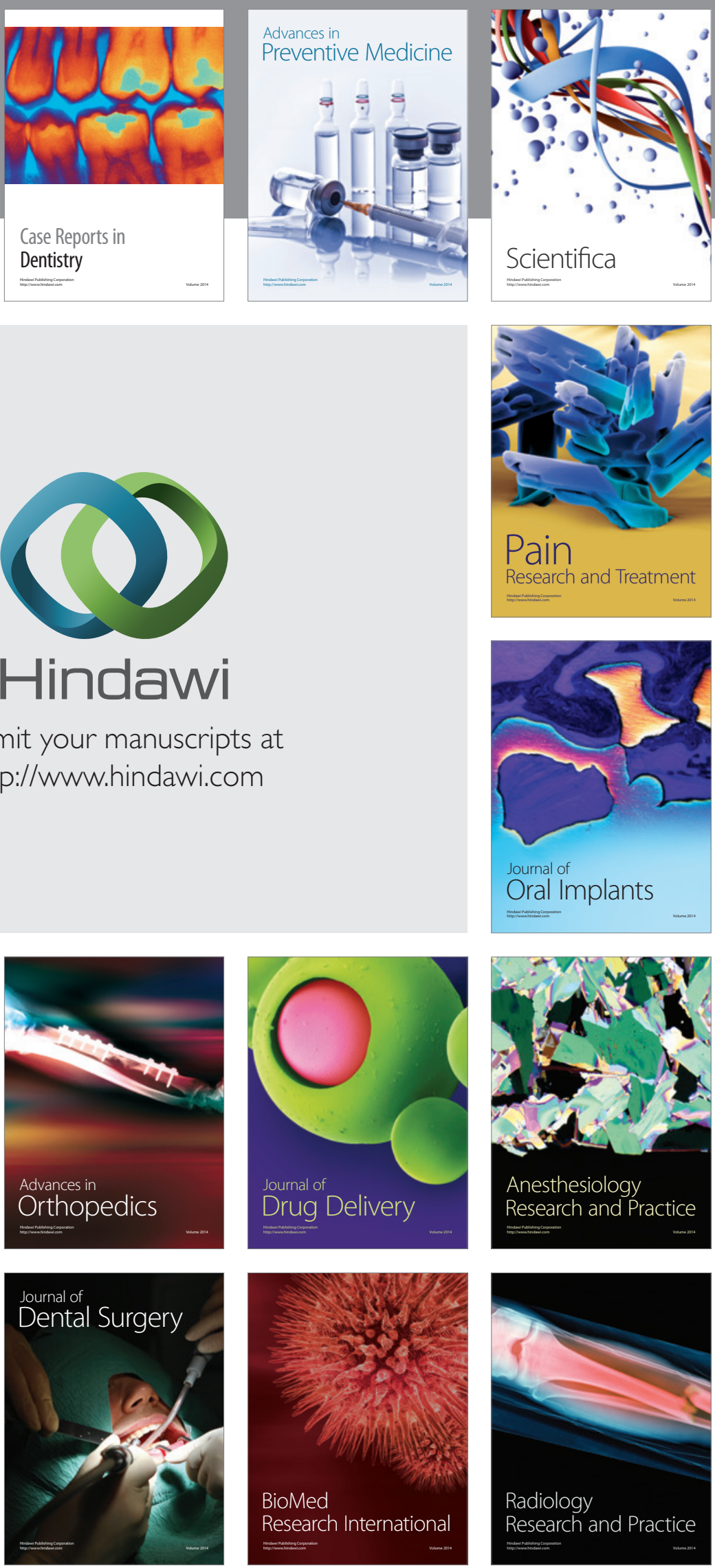